\title{
ESTRUTURA E DINÂMICA DE UMA ÁREA MANEJADA NA FLORESTA NACIONAL DO TAPAJÓS
}

\author{
Talita Godinho Bezerra ${ }^{1}$; Antônio Ozenilto de Sousa Lima²; Jéssica Thaíse Rocha de Araújo3; Milla \\ Graziely Silveira dos Santos ; Raphael Lobato Prado Neves ${ }^{5}$; Giselli Castilho Moraes; \\ Melo ${ }^{7}$. \\ 1Universidade Federal Rural da Amazônia (UFRA), Belém, Pará, Brasil, talita.gbezerra@gmail.com \\ ¿Universidade Federal Rural da Amazônia (UFRA), Belém, Pará, Brasil, aoslima@gmail.com \\ 3Universidade Federal do Oeste do Pará (UFOPA), Santarém, Pará, Brasil, jessicarocharaujo@gmail.com \\ ${ }^{4}$ Universidade Federal do Oeste do Pará (UFOPA), Santarém, Pará, Brasil, millagsilveira@gmail.com \\ 5Universidade Federal do Oeste do Pará (UFOPA), Santarém, Pará, Brasil, raphael.lobato@outlook.com \\ 6Universidade do Estado de Santa Catarina (UDESC), Lages, Pará, Brasil, giselli.moraes14@hotmail.com \\ 7Universidade Federal do Oeste do Pará (UFOPA), Santarém, Pará, Brasil, Icolivei@gmail.com
}

RESUMO: Objetivou-se, neste estudo, avaliar a estrutura e a dinâmica de uma comunidade arbórea, antes e após a intervenção florestal, na Floresta Nacional do Tapajós. Para isso, instalou-se, aleatoriamente, 10 parcelas permanentes de $50 \times 50 \mathrm{~m}$ em uma Unidade de Produção Anual (1.000 ha) e realizou-se medições antes e após a intervenção, nos anos de 2012 e 2015, respectivamente. A análise revelou que a extração de madeira provocou alteração no número de indivíduos, área basal e volume, porém não afetou a distribuição diamétrica dos indivíduos arbóreos. $\bigcirc$ crescimento médio anual em diâmetro, considerando todas as árvores com DAP $\geq 10$ $\mathrm{cm}$, ficou em torno de 0,34 cm.ano-1. As árvores com copas totalmente expostas à luz, ausentes de cipó e sem danos, cresceram mais que as sombreadas, com cipós e danos restringindo seu crescimento. A mortalidade foi superior aos ingressos de novas árvores, refletindo um balanço negativo comum em áreas recém exploradas. Após a intervenção, a floresta estudada conseguiu manter suas características semelhantes à floresta original.

PALAVRAS-CHAVE: Crescimento de florestas, Manejo florestal, Parcelas permanentes.

\section{STRUCTURE AND DYNAMICS OF A MANAGED AREA IN TAPAJÓS NATIONAL FOREST}

ABSTRACT: The objective of this study was to evaluate the structure and dynamics of a tree community, before and after the forest intervention, in the Tapajós National Forest. To this end, 10 permanent plots of $50 \times 50 \mathrm{~m}$ were settled randomly on an Annual Production Unity (1,000 ha) and measurements were performed before and after the intervention, in 2012 and 2015, respectively. The analysis showed that logging caused changes in the number of trees, basal area and volume, but did not affect the 
diametric distribution of trees. The annual average growth in diameter, considering all trees with $\mathrm{DBH} \geq 10 \mathrm{~cm}$, was approximately $0.34 \mathrm{~cm}$.year-1. Trees with tops fully exposed to light, without lianas and undamaged, grew more than the shaded ones, with lianas and damages restricting its growth. Mortality was higher than the admission of new trees, reflecting a common negative balance in new explored areas. After the intervention, the studied forest managed to maintain its characteristics similar to the original forest.

KEYWORDS: Forest growth, Forest management, Permanent plots.

\section{ESTRUCTURA Y DINÁMICA DE UN ÁREA MANEJADA EN EL BOSQUE NACIONAL DEL TAPAJÓS}

RESUMEN: En este estudio, se evaluó la estructura y la dinámica de una comunidad arbórea, antes y después de la intervención forestal, en el Bosque Nacional del Tapajós. Para ello, se instalaron aleatoriamente 10 parcelas permanentes de 50 × 50 m en una Unidad de Producción Anual (1.000 ha) y se realizaron mediciones antes y después de la intervención, en los años 2012 y 2015, respectivamente. El análisis reveló que la extracción de madera provocó alteración en el número de individuos, área basal y volumen, pero no afectó la distribución diamétrica de los individuos arbóreos. El crecimiento medio anual en diámetro, considerando todos los árboles con DAP $\geq$ $10 \mathrm{~cm}$, se situó en torno a 0,34 cm.ano-1. Los árboles con copas totalmente expuestas a la luz, ausentes de cipó y sin daños, crecieron más que las sombreadas, con cipos y daños restringiendo su crecimiento. La mortalidad fue superior a los ingresos de nuevos árboles, reflejando un balance negativo común en áreas recién explotadas. Después de la intervención, el bosque estudiado logró mantener sus características semejantes al bosque original.

PALABRAS CLAVES: Crecimiento de bosques, Manejo forestal, Parcelas permanentes.

\section{INTRODUÇÃO}

A Floresta Nacional do Tapajós (Flona do Tapajós), é uma unidade de conservação federal localizada na Amazônia. É uma das pioneiras em estudos de monitoramento florestal através do programa de monitoramento de florestas, lançado pela Empresa Brasileira de Pesquisa Agropecuária (EMBRAPA) na década de 1980 (SILVA; LOPES, 1984). Atualmente, para cumprir as exigências 
da certificação florestal no desenvolvimento de atividades de manejo florestal, a Cooperativista Mista da Flona do Tapajós (COOMFLONA) instala, todos os anos, um conjunto de parcelas permanentes na área.

As parcelas permanentes são instrumentos que permitem monitorar as mudanças que ocorrem na estrutura da floresta e o estoque remanescente, além de fornecer informações qualitativas e quantitativas visando garantir que o povoamento florestal tenha capacidade para produzir, ao longo das gerações, um estoque compatível ao explorado, o que constitui também um desafio atual e futuro da pesquisa para a conservação dos recursos florestais (SOUZA et al., 2015).

De acordo com Carvalho (1997) e Reis et al. (2013), a fitossociologia e o monitoramento da dinâmica da floresta são ferramentas imprescindíveis para avaliar a extensão dos impactos da exploração madeireira na floresta remanescente e sua capacidade de se recuperar para a próxima colheita.

O monitoramento da dinâmica pode resumir-se no entendimento do comportamento das taxas de crescimento, recrutamento e mortalidade dos indivíduos arbóreos, em condições naturais ou sob manejo. Informações que são fundamentais para definição do ciclo de corte do manejo florestal, intensidade de colheita e para realização de tratamentos silviculturais nas florestas manejadas (ROCHA, 2001),

Com base nestas e outras ferramentas e visando contribuir para o conhecimento sobre o manejo florestal na Amazônia, este trabalho objetivou avaliar a estrutura e a dinâmica de uma comunidade arbórea, entre o período de 2012 a 2015, antes e após a intervenção florestal, na Floresta Nacional do Tapajós.

\section{MATERIAL E MÉTODOS}

O trabalho foi realizado na Floresta Nacional do Tapajós no estado do Pará, localizada às margens da Rodovia 
Santarém-Cuiabá (BR 163). Situada entre as coordenadas geográficas de $2^{\circ} 45^{\prime}$ e $4^{\circ} 15^{\prime}$ de Latitude Sul e 544' e 55030' de Longitude Oeste, com área de aproximadamente $\quad 530.000$ hectares, que abrange parte dos municípios de Belterra, Placas e Rurópolis (GONÇALVES; SANTOS, 2008).

O clima da região, segundo a classificação de Köppen, é do tipo Am, quente e úmido, com temperatura média anual de $25,5^{\circ} \mathrm{C}$. A precipitação média anual está em torno de 1.820 mm com maior intensidade nos meses de janeiro a maio. Os solos da região são classificados como Latossolo Amarelo distrófico, profundos com baixa capacidade de troca catiônica. A Flona do Tapajós está em zona de Floresta Ombrófila Densa, tipo de vegetação predominante no norte do país (IBAMA, 2005).

Os dados são provenientes das parcelas permanentes de monitoramento instaladas nas proximidades do km 67 da BR 163, mais precisamente na Unidade de Produção
Anual (UPA) 08 da Área de Manejo Florestal (AMF) da Cooperativa Mista da Flona do Tapajós.

A UPA 08 tem área de 1.000 hectares dividida em 10 Unidades de Trabalho (UT), onde foi instalado uma parcela permanente para cada UT, aleatoriamente, conforme as diretrizes propostas Silva et al. (2005). Cada parcela possui $50 \times 50$ m, subdividida em 25 subunidades de $10 \times 10 \mathrm{~m}$, totalizando 0,25 ha cada. A primeira medição foi realizada antes da exploração e a segunda dois anos após o término da intervenção na floresta, respectivamente, nos anos de 2012 e 2015.

Para o monitoramento das parcelas foram consideradas as árvores com diâmetro à altura de 1,30 m do solo $(D A P) \geq 10,0 \mathrm{~cm}$, medidas em toda parcela de 50 × 50 m. A delimitação das parcelas e subparcelas foi feita com piquetes de tubo PVC, os quais foram pintados com tinta óleo de cor vermelha para facilitar a sua localização. Todas as árvores inventariadas tiveram como variáveis 
coletadas: Nome vulgar, identificado por parabotânicos; Circunferência à altura do peito (CAP) em milímetros; Classe de identificação do fuste (CIF); Situação silvicultural (SIT); Iluminação e forma da copa; Presença de danos; Presença e efeito de cipós; e, Presença de podridão.

Os dados coletados foram compilados e processados no Programa MFT (Monitoramento de Florestas Tropicais). Foram estimados, então, os parâmetros estruturais fitossociológicos, tais como composição de espécies, índice de valor de importância (IVI), densidade $\left(n \cdot h a^{-1}\right)$, área basal $\left(m^{2} \cdot h a^{-1}\right)$ e volume $\left(\mathrm{m}^{3}\right.$. ha $\left.{ }^{-1}\right)$; e a dinâmica da comunidade arbórea expressa pelos índices de diversidade (Diversidade de Shannon, Similaridade de Jaccard, Equabilidade de Pielou), incremento, mortalidade e ingresso.

As análises estatísticas foram realizadas com o auxílio dos softwares Microsoft Office Excel e BioEstat. Os testes de hipóteses de Shapiro-Wilk foram realizados para avaliar as suposições de normalidade e o teste de Bartlett para verificar a homocedasticidade de variâncias, respectivamente, exigidas pelos testes paramétricos. Foram utilizados o teste $t$ de Student e Análise de Variância (ANOVA), e quando as suposições de normalidade e homocedasticidade dos dados não foram atingidas, foram utilizados os testes não paramétricos de Wilcoxon e Kruskal-Wallis, afim de comparar as taxas de crescimento diamétrico.

\section{RESULTADOS E DISCUSSÕES}

Em 2012, nas 10 parcelas amostradas, foram registradas 157 espécies (19 não identificadas), 96 gêneros e 43 famílias botânicas. Após três anos (2015), houve redução de 5 espécies e dois gêneros, sendo o número de famílias igual ao da primeira medição.

Antes da exploração, as famílias mais importantes em riqueza de espécies foram: Fabaceae (22,93\%), Lauraceae (5,73\%) e Lecythidaceae (5,10\%), seguido de Annonaceae, 
Burseraceae e Moraceae, cada uma como 3,82\% da riqueza em espécies amostrada. Estas cinco famílias representam conjuntamente 57,32\% de todos os indivíduos estudados. No último monitoramento (após a extração de madeira), o ranking de famílias mais importantes na área permaneceu o mesmo, porém Fabaceae com 23,03\% das espécies, Lauraceae (5,92\%), Lecythidaceae (5,26\%) e, Annonaceae, Burseraceae e Moraceae com 3,95\% cada.

Os resultados de composição florística desse estudo corroboram com as observações de Espírito-Santo et al. (2005) na Flona do Tapajós, o qual destacou como famílias mais importantes de sua área de estudo, Fabaceae, Moraceae, Lauraceae e Lecythidaceae. Segundo Ruschel (2008), na Floresta de Terra Firme da Flona do Tapajós, é notória a dominância das Leguminosas, Lecythidaceae, Sapotaceae, Meliaceae, Lauraceae, Burseraceae e Moraceae. Lima Filho et al. (2004), e Oliveira e
Amaral (2004) também identificaram essas mesmas famílias botânicas em florestas nativas da Amazônia a nível de importância em riqueza e diversidade.

Na Figura 1 são demonstradas as 10 espécies de maior valor de importância antes da intervenção (2012) e após a intervenção (2015) na unidade de produção anual 8. As dez espécies mais importantes na comunidade florestal estudada, nos dois períodos analisados, foram Sclerolobium sp. Vogel, Eschweilera sp. Mart. ex DC., Guatteria poeppigiana Mart., Maquira sp. Aubl., Virola sp. Aubl., Alexa grandiflora Ducke, Couratari guianensis Aubl., Protium sp. Burm. f., Protium paniculatum Engl., Chimarrhis turbinata DC. Dentre elas, as espécies com os maiores IVI foram Taxi Pitomba (Sclerolobium sp.), com valor de 16 no ano de 2015; Matamatá-preto (Eschweilera sp.) com valor de 13,6 e Envira preta (Guatteria poeppigiana) com valor de 11,5 após a intervenção. 
Figura 1. Espécies de maior valor de importância encontradas em dois períodos, antes e depois da colheita florestal, nas parcelas permanentes da UPA 8.

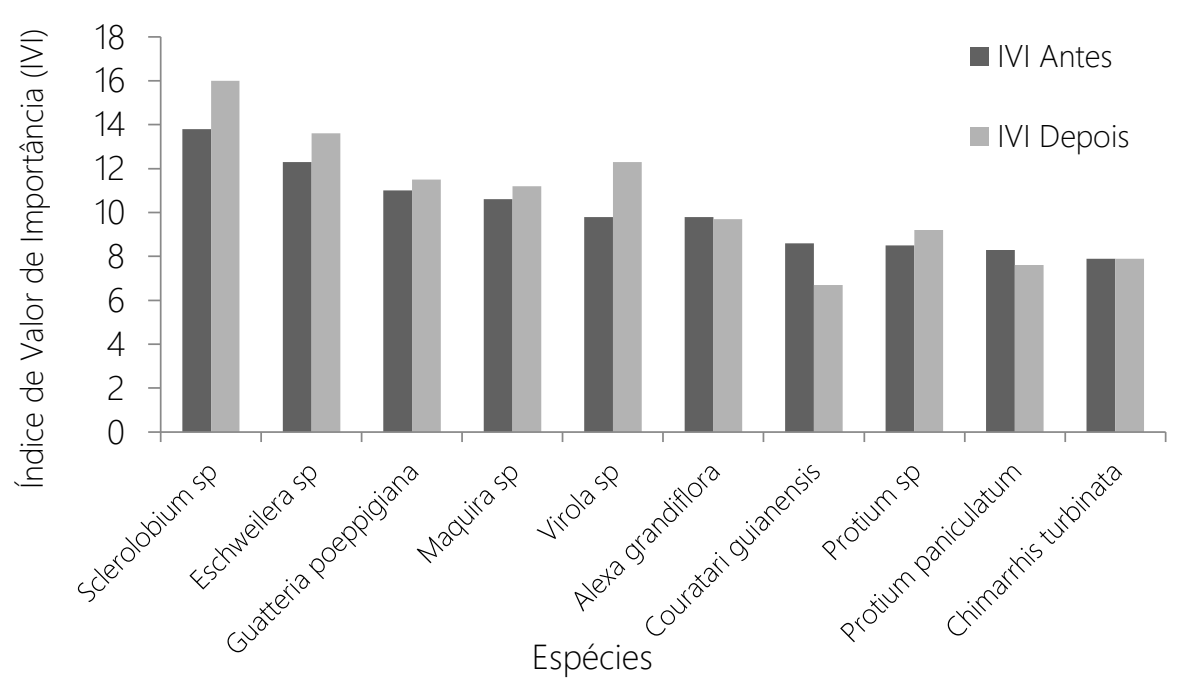

Fonte: Elaborado pelo autor.

A manutenção da estrutura da a manutenção da estrutura da floresta floresta, antes e após a exploração, está relacionada à boa distribuição horizontal das espécies, principalmente daquelas mais frequentes e dominantes, que são fundamentais nos processos básicos de equilíbrio da floresta (OLIVEIRA; AMARAL, 2004; SILVA et al., 2008).

Não houve diferença estatística significativa entre os valores de IVI para a floresta antes da intervenção (2013) e após a intervenção (2015) de acordo com o teste $t$ ao nível de $5 \%$ de probabilidade, o que indica que houve (Figura 1). A espécie comercial tauari (Couratari guianensis), uma das extraídas durante a colheita de madeira, apresentou o IVI um pouco abaixo do valor anterior à intervenção (antes 8,6 e após 6,7), mas se manteve entre as dez espécies de maior importância.

Em uma floresta de terra firme localizada no município de Paragominas (PA), Francez et al. (2009) também relatou que os valores de IVI mantiveram-se parecidos para as espécies mesmo após a intervenção. 0 
reduzido número de espécies mais (2012), 390,8 árvores.ha ${ }^{-1}, 23,41 \mathrm{~m}^{2} \cdot \mathrm{ha}^{-1}$ importantes encontrado no estudo, de área basal e 242,88 $\mathrm{m}^{3}$.ha-1 de representa uma grande parcela de volume. Na medição realizada após a contribuição para o índice de valor de extração de madeira (2015), os valores importância desta floresta (MORI et foram 342,8 árvores.ha-1, 20,36 m².ha-1 al.,1989; ROCHA, 2001; FRANCEZ et al., 2009).

A floresta analisada apresentou, em média, no primeiro ano de medição e 209,02 $\mathrm{m}^{3} \cdot h a^{-1}$. Ocorreu diminuição do número de indivíduos antes e após a exploração, principalmente nas primeiras classes diamétricas (Figura 2).

Figura 2. Distribuição do número de árvores por classe de diâmetro em dois períodos.

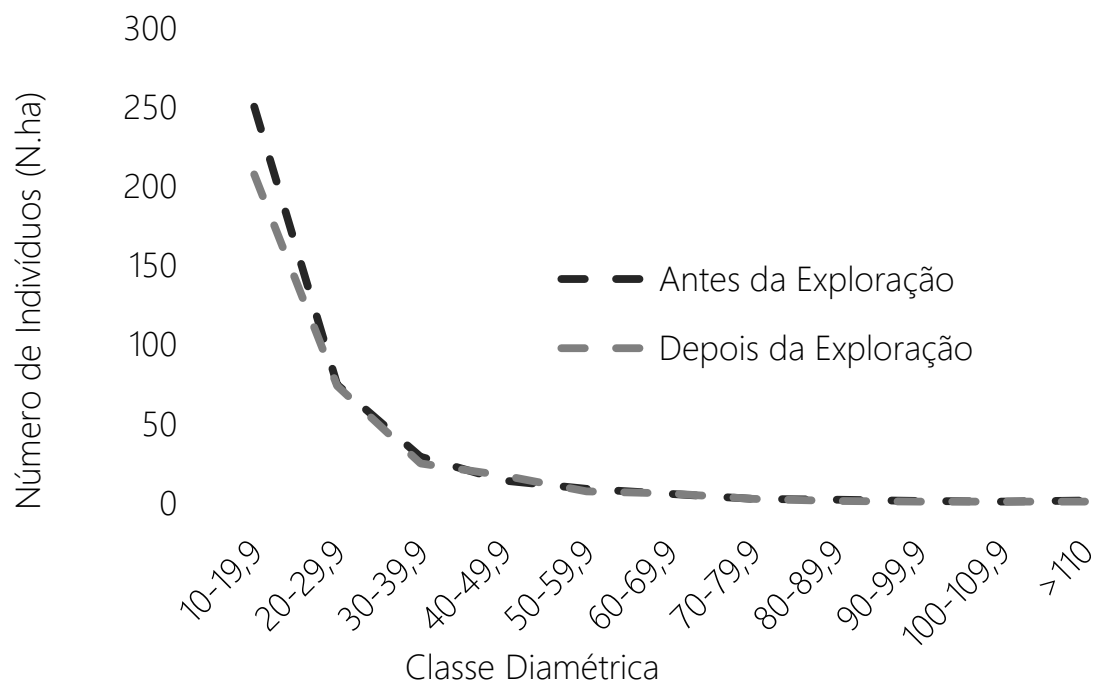

Fonte: Elaborado pelo autor.

Após três anos, observa-se que as variáveis apresentaram uma redução, sendo, a extração madeireira, ocorrida nesse intervalo de tempo, a principal responsável por essa alteração. A distribuição do número de indivíduos 
arbóreos seguiu o padrão "j" invertido, curva que melhor descreve a estrutura diamétrica das florestas da região amazônica, ou seja, florestas inequiâneas. Nesse padrão, a população analisada possui representantes em todas as classes de tamanho (AMARAL et al., 2000; LIMA FILHO et al., 2001; BERNASOL; LIMARIBEIRO, 2010), porém ocorre a maior concentração de indivíduos nas primeiras classes de diâmetro e redução progressiva à medida que se eleva o DAP. Além disso, observou-se que a extração de madeira não afetou a distribuição e que a floresta manteve a sua estrutura original.

O índice de similaridade do estrato arbóreo entre os períodos analisados foi obtido pelo índice de Jaccard, revelando um valor de 0,96 entre as medições de 2012 e 2015, ou seja, houve alta similaridade florística entre as espécies de árvores analisadas, sendo 151 espécies em comum, seis espécies exclusivas da primeira medição e uma da segunda.
Ao avaliar o impacto da exploração florestal em uma floresta no município de Paragominas no estado do Pará, Francez et al. (2009) também encontrou 0,96 de similaridade entre duas ocasiões, porém pelo índice de Sorensen. Na Flona do Tapajós, um trecho de floresta sob regime de manejo apresentou no período de três anos (2006-2009) um valor de 0,98, ou seja, alta similaridade florística entre a ocasião pré e pós exploração (KROESSIN, 2013), corroborando com os resultados deste estudo.

O índice de Shannon $\left(H^{\prime}\right)$ revelou uma diversidade de 4,8 na primeira medição e 4,5 na segunda, não sendo possível constatar diferenças estatísticas significativas de acordo com o teste de Wilcoxon, onde o valor de (p) foi de 0,0284 a um nível de 1\% de probabilidade. Para a equabilidade de Pileou ( $\left.E^{\prime}\right)$ os valores mantiveram-se constantes durante as ocasiões, comprovando que a extração de madeira não alterou de forma significativa os padrões de diversidade da floresta. 
Resultados semelhantes foram encontrados por Alves; Miranda (2008), cujo índice foi de $H^{\prime}=4,25$ em uma floresta de terra firme sob exploração florestal na Amazônia; e por Oliveira; Amaral (2004) na região de Manaus, cujo índice de diversidade foi superior com $H^{\prime}$ 5,0. De maneira geral, os resultados mostram que há elevada diversidade florística na área, pois florestas que apresentam valores de $\mathrm{H}^{\prime}$ acima de 3,5 são consideradas de alta diversidade (FLORIANO, 2014).

No período de três anos de observação da floresta, a média de incremento periódico anual (IPA) em DAP foi de 0,34 cm.ano-1, considerando todas as espécies arbóreas com DAP $\geq 10 \mathrm{~cm}$. A taxa de incremento em área basal para o período de 2012 a 2015, considerando as árvores com DAP $\geq 10 \mathrm{~cm}$, foi de 0,4459 $\mathrm{m}^{2} / \mathrm{ha}$ /ano. $\mathrm{O}$ incremento volumétrico foi de $5,43 \mathrm{~m}^{3} / \mathrm{ha}$ /ano para a população arbórea analisada nesse estudo.

Analisando o incremento médio em diâmetro na Flona do Tapajós, Costa et al. (2008) obteve 0,30 cm.ano-1 para todas as espécies de árvores com DAP $\geq 5 \mathrm{~cm}$, valor semelhante ao do presente estudo. Em estudo que objetivou analisar um trecho da Flona do Tapajós sem exploração madeireira, em um período de 22 anos, Oliveira et al. (2005) obteve incremento médio em diâmetro de 0,14 cm.ano ${ }^{-1}$ para toda população arbórea com DAP $\geq 5 \mathrm{~cm}$. Por outro lado, Vidal et al. (2002) em uma área de floresta sob intervenção, obteve árvores com DAP $\geq 5 \mathrm{~cm}$ crescendo em média 0,63 cm.ano-1, considerando somente 3 anos de observação.

Esses resultados traduzem a dificuldade em comparar taxas de crescimento em florestas tropicais, uma vez que vários fatores intrínsecos ou extrínsecos interferem no crescimento de árvores individuais e refletem na variedade de incrementos encontrados (SILVA, 1989).

A taxa de incremento em área basal para o período de 2012 a 2015 deste estudo, considerando as árvores com DAP $\geq 10 \mathrm{~cm}$, é semelhante ao 
encontrado por Kroessin (2013) totalmente sombreados (16,35\%). também na Flona do Tapajós, cujo Considerando o incremento das incremento em área basal foi de 0,4921 árvores de acordo com a iluminação $\mathrm{m}^{2} / \mathrm{ha}$ /ano para árvores com DAP $\geq 10$ recebida, houve diferença significativa cm, no período de 2006 a 2012.

Os indivíduos arbóreos entre as taxas de iluminação, sendo o valor de (p) 0,0050 de acordo com a completamente expostos à luz ANOVA a um nível de $1 \%$ de apresentaram maior crescimento em probabilidade; a incidência de luz total diâmetro (54,81\%) do que os beneficiou o incremento em diâmetro parcialmente encobertos (28,85\%) e (Figura 3).

Figura 3. Taxa de crescimento médio das árvores conforme a intensidade de luz recebida.
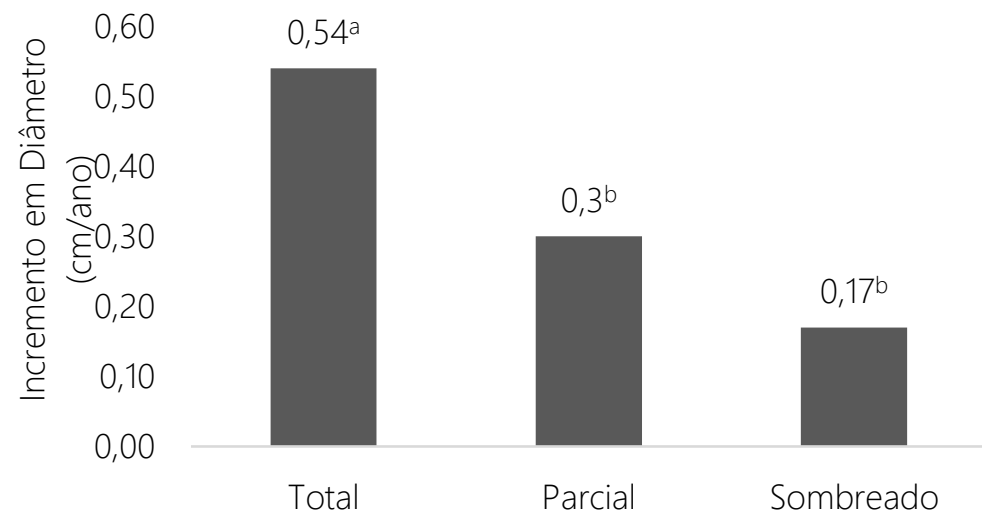

Total

Intensiade luminosa

Fonte: Elaborado pelo autor.

A luminosidade recebida pelas luz apresentaram maior crescimento copas das árvores é um grande em diâmetro do que as parcialmente propulsor de crescimento, logo, na encobertas e totalmente sombreadas. floresta em estudo, os indivíduos Resultados semelhantes a esses arbóreos completamente expostos à foram encontrados por Vatraz et al. 
(2016) ao analisarem o incremento em diâmetro de árvores com DAP $\geq 10 \mathrm{~cm}$ sob diferentes níveis de exposição à luz solar em um trecho de floresta no Município de Paragominas, Pará. Os autores constaram que os indivíduos totalmente expostos à luz cresceram $0,50 \mathrm{~cm}^{2}$ ano ${ }^{-1} ; 0,27 \mathrm{~cm}$ ano-1 aqueles que receberam algum tipo de luminosidade e 0,12 cm.ano-1 aqueles completamente sombreados. Esse efeito da exposição das copas de árvores à luz também foi encontrado por Vidal et al. (2002) em uma floresta tropical sob regime de manejo na Amazônia Oriental e, por Oliveira e Braz (2006), na Amazônia Ocidental

$\mathrm{Na}$ área de estudo, verificou-se que no período de três anos de acompanhamento, árvores com cipó representaram 36,23\% da população arbórea analisada. $\bigcirc$ incremento anual foi de $0,41 \mathrm{~cm}$.ano-1 para árvores sem cipó, sendo 31,70\% maior que o incremento alcançado por árvores com cipó presente e sem causar danos $(0,28$ $\mathrm{cm}^{\mathrm{anno}} \mathrm{-}^{-1}$ ) (Figura 4).

Figura 4. Incremento em diâmetro das árvores de acordo com o grau de infestação de cipó. Sendo: I, sem cipós; II, cipós presentes sem causar danos; III, cipós presentes restringindo crescimento.

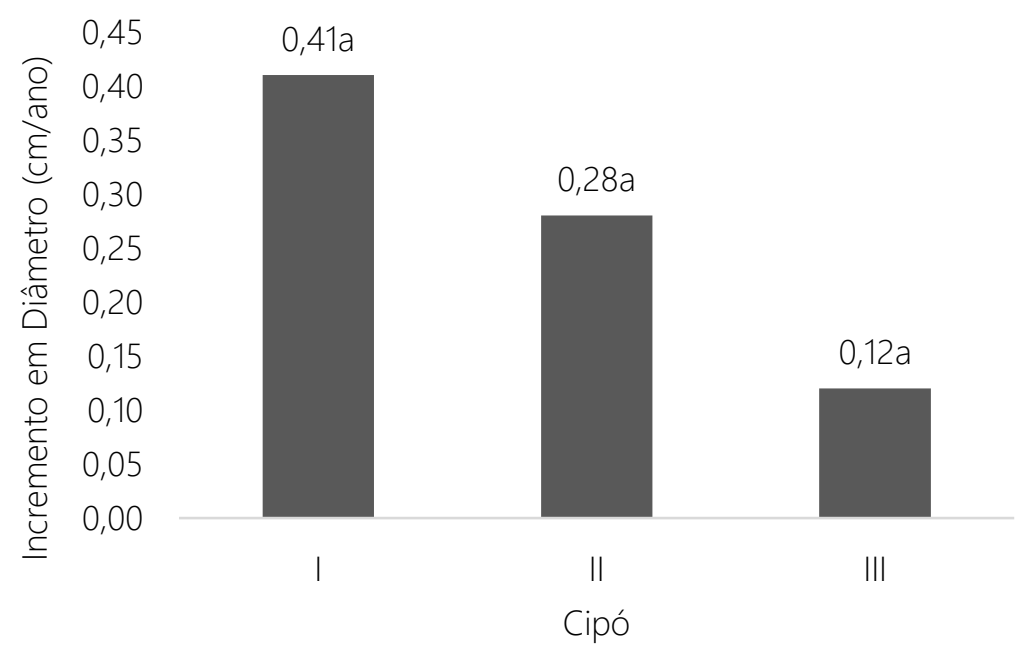

Fonte: Elaborado pelo autor. 
A presença ou ausência de cipó é outro fator que afeta o crescimento em diâmetro das árvores em florestas tropicais. Segundo Silva et al. (2005) a infestação de cipós pode ser ocasionada pelas aberturas no dossel provocado por vendavais, por exploração sem planejamento e até mesmo por desbastes com grandes intensidades.

Constatou-se também, que os cipós fortemente entrelaçados, restringiram o crescimento das árvores, que apresentaram incremento anual em diâmetro de apenas 0,12 cm.ano-1, valor bastante inferior ao daquelas árvores sem a presença de cipós ou com cipós presentes, porém sem causar danos. Apesar disso, não foi captada diferença estatística entre as situações por meio da ANOVA ( $p=0,1009)$, fato este que pode ser explicado pela alta variabilidade obtida entre as parcelas.

Com relação aos danos, 87\% dos indivíduos não apresentaram nenhum dano; $12 \%$ com danos classificados como leves, ocasionados por causas naturais, tais como tempestades, vendavais e mortalidade de indivíduos próximos; e, 0,1\% com danos leves ocasionados pela exploração de madeira (maquinários e/ou derruba). Não foram identificados indivíduos com danos severos, seja por causa natural ou pela intervenção florestal.

Observou-se que a taxa de crescimento em diâmetro das árvores que estavam livres de danos foi de 0,37

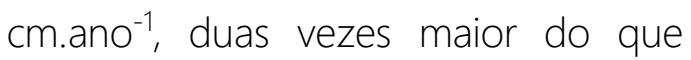
aquelas que apresentaram danos leves $\left(0,19 \mathrm{~cm}^{\mathrm{anno}}{ }^{-1}\right)$. De acordo com o teste de Kruskal-Wallis houve diferença significativa entre o crescimento de árvore sem danos e com danos leves por causa natural ou por exploração, ao nível de 1\% de probabilidade (Figura 5).

Em um estudo na Flona do Tapajós durante cinco anos de observação, indivíduos sem danos cresceram em média 0,32 $\mathrm{cm}$ ano ${ }^{-1}$, valor maior que o incremento de árvores com danos leves (COSTA et al., 2008) assemelhando-se aos valores encontrados neste estudo.

Durante o período de avaliação (2012-2015), verificou-se que a mortalidade foi superior ao 
recrutamento de novas árvores na da mortalidade natural, causada pela Unidade de Produção Anual 8 (Figura ação dinâmica da floresta, inclui-se a 6). O balanço negativo entre as taxas de mortalidade ocasionada pelas mortalidade e recrutamento é esperado operações de colheita (derruba, arraste em áreas recém-exploradas, pois além de toras, etc.).

Figura 5. Incremento em diâmetro das árvores por classe de dano. Sendo: I, ausente de danos; II, danos leves ocasionados por causas naturais; III, danos leves ocasionados pela exploração de madeira.
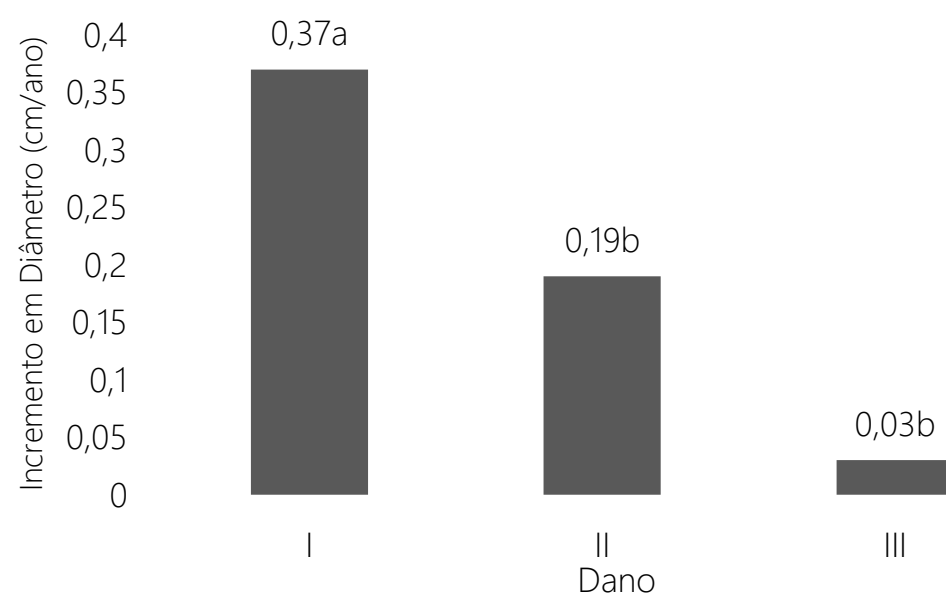

Dano

III

Fonte: Elaborado pelo autor.

Figura 6. Porcentagem de árvores mortas e ingressantes na UPA 08.

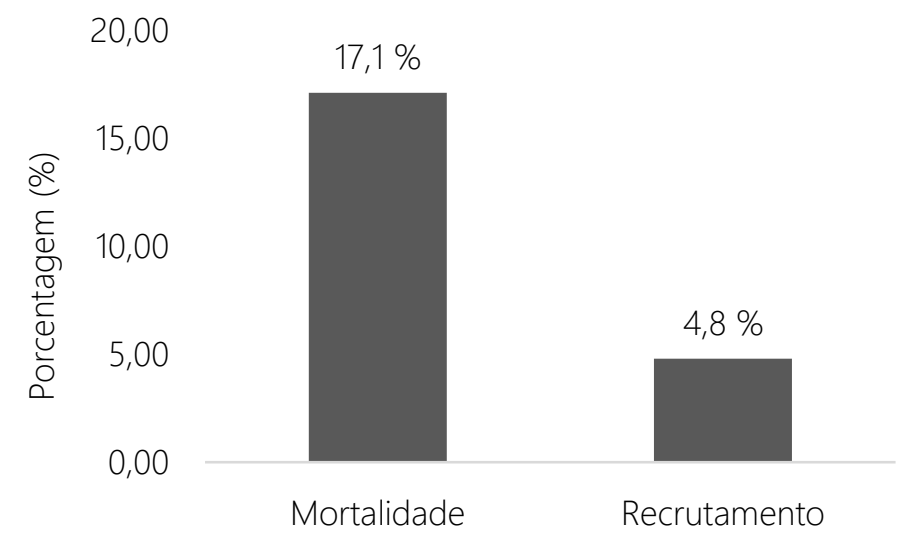

Fonte: Elaborado pelo autor. 
As variações de dinâmica que ocorrem nas comunidades podem ser mascaradas em períodos de monitoramento muito curtos (ROLIM et al., 1999). Por isso, o tempo de acompanhamento (3 anos) não foi suficiente para captar o crescimento das árvores remanescentes e da regeneração de varas e arvoretas presentes na floresta, sendo, portanto, necessário mais tempo para o recrutamento de novas árvores no local.

Foram verificadas altas taxas de mortalidade logo após a exploração, ou seja, havia maior número de árvores mortas em relação à quantidade de ingressos em um experimento de manejo florestal madeireiro, realizado na Flona do Tapajós por Oliveira et al. (2005). Além disso, o autor constatou que a mortalidade só começou a reduzir acentuadamente a partir do quinto ano após a exploração. Este fato também foi constatado por Reis et al. (2010) na Flona do Tapajós.

Quando observado a mortalidade por classes de diâmetro percebe-se que o maior percentual de árvores mortas se concentra na menor classe, aproximadamente $70 \%$ do total (Figura 7).

Figura 7. Mortalidade das árvores de acordo com as classes de DAP após a colheita de árvores.

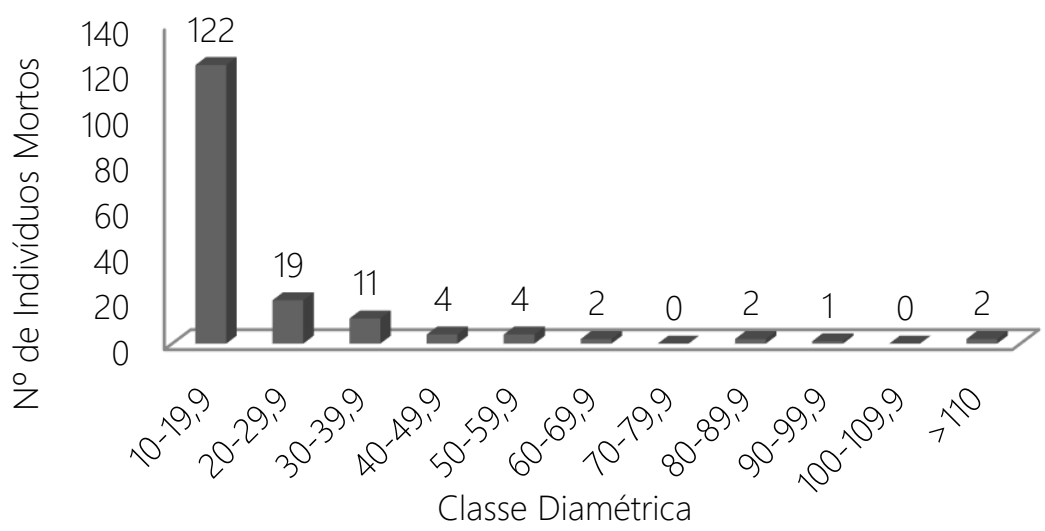

Fonte: Elaborado pelo autor. 
Esse resultado se dá em virtude desses indivíduos serem mais suscetíveis aos danos ocasionados pelas operações de colheita e aos danos naturais, como as tempestades, por exemplo. Além disso, Silva (1989) afirma que em florestas exploradas, a mortalidade tende a ser maior nas classes inferiores de tamanho e que depois de algum tempo, após a maioria das espécies pioneiras terem sido substituídas por espécies tolerantes à sombra, a mortalidade tende a estabilizar-se.

\section{CONCLUSÃO}

A diversidade e a similaridade florística, antes e depois da exploração, mostram-se pouco alteradas, indicando que a intensidade da exploração foi baixa, causando o mínimo de impacto à comunidade arbórea;

De maneira geral, a comunidade arbórea analisada apresenta resultados satisfatórios de incremento em diâmetro, área basal e volume, mesmo após passar por intervenção;
A floresta, dois anos após a exploração, permanece com características semelhantes a original. Os resultados encontrados indicam que a exploração de impacto reduzido possibilitou a manutenção da estrutura e da dinâmica da floresta durante as ocasiões estudadas.

\section{AGRADECIMENTOS}

À Cooperativa Mista da Flona do Tapajós pelo apoio logístico para a realização da pesquisa, através do Projeto "Monitoramento da estrutura e dinâmica florestal em áreas submetidas à manejo para exploração de madeira na Floresta Nacional do Tapajós" realizado em parceria com a Universidade Federal do Oeste do Pará e colaboradores.

\section{REFERÊNCIAS}

ALVES, J. C. Z. O.; MIRANDA, I. S. Análise da estrutura de comunidades distância geográfica na riqueza e composição de espécies arbóreas de uma floresta amazônica de Terra Firme aplicada ao arbóreas em uma Floresta Ombrófila Densa na Amazônia manejo 
florestal. Acta Amazonica, Manaus, v. 38, p. 657-666, 2008.

AMARAL, I. L.; MATOS, F. D. A.; LIMA, J. Composição florística e estrutural de um hectare de floresta densa de terra firme no Rio Uatumã, Amazônia, Brasil. Acta Amazonica, Manaus, v.30, n. 3, p. 377-392, 2000.

BERNASOL, W. P.; LIMA-RIBEIRO, M. S. L. Estrutura espacial e diamétrica de espécies arbóreas e seus condicionantes em um fragmento de cerrado sentido restrito no sudoeste goiano. Hoehnea, São Paulo, v. 37, n. 2, p.181-198, 2010.

CARVAlHO, J. O. P. de. Dinâmica de florestas naturais e sua implicação para o manejo florestal. In: CURSO DE MANEJO FLORESTAL SUSTENTÁVEL, 1997, Curitiba. Tópicos em manejo florestal sustentável. Colombo: EMBRAPA-CNPF, 1997.

COSTA, D. H. M; SILVA, J. M. N; CARVALHO, J. O. P. Crescimento de árvores em uma área de terra firme na Floresta Nacional do Tapajós após a colheita de madeira. Revista Ciências Agrárias, Belém, n. 50, p. 63-76, 2008.

ESPIRÍTO-SANTO, F. D. B; SHIMABUKURO, E.; ARAGÃO, L. E. O. C.; MACHADO, E. L. M. Análise da Composição florística e fitossociológica da floresta nacional do Tapajós com o apoio geográfico de imagens de satélites. Acta Amazonica, Manaus, v. 35, n. 2, p. 155-173, 2005.
FLORIANO, E. P. Fitossociologia Florestal, 1.ed. São Gabriel: Unipampa, 2014. 136 p.

FRANCEZ, L. M. B.; CARVALHO, J. O. P.; JARDIM, F. C. S.; QUANZ, B.; PINHEIRO, K. A. O. Efeito de duas intensidades de colheita de madeira na estrutura de uma floresta natural na região de Paragominas, Pará. Acta Amazônica, Manaus, v.39, p. 851-864, 2009.

GONÇALVES, F. G.; SANTOS, J. R. Composição florística e estrutura de uma unidade de manejo florestal sustentável na Floresta Nacional do Tapajós, Pará. Acta Amazônica, Manaus, v.38, p. 229-244, 2008.

IBAMA. Instituto Brasileiro do Meio Ambiente e dos Recursos Naturais Renováveis. Floresta Nacional do Tapajós - Plano de Manejo. Belterra, Pará, p. 200, 2005.

KROESSIN, A. Estrutura e dinâmica de uma floresta tropical submetida à exploração de impacto reduzido em Belterra, Pará. Manaus, 2013. 140 p. Dissertação (Mestrado em Ciências Florestais e Ambientais) Faculdade de Ciências Agrárias, Universidade Federal do Amazonas - UFAM, 2013.

LIMA FILHO, D. A.; MATOS, F. D. A.; AMARAL, I. L.; REVILLA, J.; COELHO, L. S.; RAMOS, J. F.; SANTOS, J. L. Inventário florístico de floresta ombrófila densa de terra firme, na região do Rio Urucu-Amazonas, Brasil. Acta Amazônica, Manaus, v. 31, p. 565579, 2001. 
LIMA FILHO, D. A.; REVILLA, J.; AMARAL, I. L.; MATOS, F. D. A.; COÊLHO, L. S.; RAMOS, J. F.; SILVA, G. B.; GUEDES, J. O. Aspectos florísticos de 13 hectares da área de Cachoeira Porteira-PA. Acta Amazônica, Manaus, v. 34, n. 3, p. 415-423, 2004.

MORI, S. A.; RABELO, B. V.; TSOU, C.; DALY, D. Composição e estrutura de uma floresta amazônica oriental em Camaipi, Amapa, Brasil. Boletim do Museu Paraense Emílio Goeldi, Belém, v. 5, n 1., p. $3-18,1989$.

OLIVEIRA, A. N.; AMARAL, I. L. Florística e fitossociologia de uma floresta de vertente na Amazônia Central, Amazonas, Brasil. Acta Amazônica, Manaus, v. 34, p. 21-34, 2004.

OLIVEIRA, L. C; COUTO, H. T. Z; SILVA, J. N. M; CARVALHO, J. O. P. Efeito da exploração madeireira e tratamentos silviculturais na composição florística e diversidade de espécies em uma área de 136 ha na Floresta Nacional do Tapajós, Belterra, Pará. Scientia Forestalis, Piracicaba, v.69, p. 62-75, 2005.

OLIVEIRA, M. V. N.; BRAZ, E. M. Estudo da dinâmica da floresta manejada no projeto de manejo florestal comunitário do PC Pedro Peixoto na Amazônia Ocidental. Acta Amazônica, Manaus, v. 36, n. 2, p. 177-182, 2006.

REIS, L. P.; RUSCHEL, A. R.; COELHO, A. A.; LUZ, A. S. da; MARTINS-DA-SILVA, R. C. V. Avaliação do potencial madeireiro na Floresta Nacional do Tapajós após 28 anos da exploração florestal. Pesquisa Florestal Brasileira, Colombo, v. 30, n. 64, p. 265 - 281, 2010.

REIS, L. P.; SILVA, J. N. M.; REIS, P. C. M. R.; CARVALHO, J. O. P. C.; QUEIROZ, W. T.; RUSCHEL, A. R. Efeito da exploração de impacto reduzido em algumas espécies de Sapotaceae no leste da Amazônia. Floresta, Curitiba, v. 43, n. 3, p. 395-406, 2013.

ROCHA, R. M. Taxas de recrutamento e mortalidade da floresta de terra firme da bacia do Rio Cuieiras na região de Manaus-AM. Manaus, AM. 2001. 49 p. Dissertação (Mestrado em Ciências Florestais e Ambientais). Universidade Federal do Amazonas -UFAM, 2001.

ROLIM, G. S.; COUTO, H. T. Z.; JESUS, R. M. Mortalidade e recrutamento de árvores na Floresta Atlântica em Linhares (ES). Scientia Forestalis, Piracicaba, v. 55, p. 49-69, 1999.

RUSCHEL, A. R. Dinâmica da composição florística e do crescimento de uma floresta explorada há 18 anos na Flona Tapajós, PA. Documentos Técnicos, Embrapa Amazônia Oriental: 2008. 57p.

SILVA, J. N. M.; LOPES, J. C. A. Inventário florestal contínuo em florestas tropicais: a metodologia utilizada pela EMBRAPA-CPATU na Amazônia brasileira. Documentos Técnicos, Embrapa, n. 33, p. 5-36, 1984.

SILVA, J. N. M. The behavior of the tropical rain forest of the Brazilian 
amazon after logging. D Phil thesis. Green College, Oxford. Oxford, 1989.

SILVA, J. N. M; LOPES, J. do. C. A.; OLIVEIRA, L. C.; SILVA, S. M. A.; CARVALHO, J. P. O.; COSTA, D. H. M.; MELO, S. M.; TAVARES, M. J. T. Diretrizes para instalação e medição de parcelas permanentes em floretas naturais da Amazônia brasileira. Belém, PA: Embrapa Amazônia Oriental, 2005. $35 \mathrm{p}$.

SILVA, K. E.; MATOS, F. D. A.; FERREIRA, M. M. Composição florística e fitossociologia de espécies arbóreas do Parque Fenológico da Embrapa Amazônia Ocidental. Acta Amazônica, Manaus, vol. 38, n. 2, p. 213-222, 2008.

SOUZA, D. V.; CARVALHO, J. O. P. de; MENDES, F. S.; MELO, L. O.; SILVA, J. N. M.; JARDIM, F. C. S. Crescimento de espécies arbóreas em uma floresta natural de terra firme após a colheita de madeira e tratamentos silviculturais, no Município de Paragominas, Pará, Brasil. Ciência Florestal, Santa Maria, v. 25, n. 4, p. 873-883, 2015.

VATRAZ, S.; CARVALHO, J. O. P.; SILVA, J. N. M.; CASTRO, T. C. Efeito da exploração de impacto reduzido na dinâmica do crescimento de uma floresta natural. Scientia Forestalis, Piracicaba, v. 44, n. 109, p. 261-271, 2016.

VIDAL, E.; VIANA, V. M.; BATISTA, J. L. F. Crescimento de floresta tropical três anos após colheita de madeira com e sem manejo florestal na Amazônia oriental. Scientia Forestalis, Piracicaba, n. 61, p. 133-143, 2002. 